\title{
Thermogravimetric and kinetic analysis of the decomposition of Solid Recovered Fuel from municipal solid waste
}

\author{
Juan A. Conesa ${ }^{*}$, Lorena Rey
}

Department of Chemical Engineering. University of Alicante.

$$
\text { P.O. Box 99, } 03080 \text { Alicante (Spain). }
$$

Phone: +(34) 965903867 Fax: +(34) 965903826

Author email address: ja.conesa@ua.es 


\section{Abstract}

The thermal decomposition of a Solid Recovered Fuel (SRF) has been studied using thermogravimetry, in order to get information about the main steps in the decomposition of such material. The study comprises two different atmospheres: inert and oxidative. The kinetics of decomposition is determined at three different heating rates using the same kinetic constants and model for both atmospheres at all the heating rates simultaneously. A good correlation of the TG data is obtained using three $\mathrm{n}^{\text {th }}$ order parallel reactions.

Keywords: kinetics, municipal solid wastes, pyrolysis, combustion, solid recovered fuel

\section{Introduction}

In Spain, as in the European Union (EU) countries, there has been an increase in per capita waste generation with the growth of the economy. Proper management prevents environmental problems, by converting waste into resources that contribute to the saving of raw materials and energy, so that good management practices together with source reduction are two of the cornerstones of policy environment.

In 2010, total waste generation in the EU-27 amounted to 2.5 billion Mg, an average of $4986 \mathrm{~kg}$ per EU inhabitant. 927 million $\mathrm{Mg}$ of this total are covered by the indicator 'generation of waste excluding major mineral wastes', corresponding to $1847 \mathrm{~kg}^{\text {inhabitant }}{ }^{-1}$ and to $37 \%$ of the generated waste total [1]. In Spain, in 2011, each person generated $490 \mathrm{~kg}$ of municipal waste, a value well below the $662 \mathrm{~kg}$ produced in the year 2000 [2]. This value is close to the average municipal waste per capita in the EU-27 (499 kg person $\left.{ }^{-1}\right)$ in the 2010.

Energy recovery from waste has become the main option for the recovery of resources contained in waste. In this sense, an effort to reuse or composting the municipal solid waste should be given, and a final energy recovery of non-reusable and non-compostable matter should be done.

Solid Recovered Fuel (SRF) is a waste derived fuel made from non-hazardous household waste. It is feasible to recover energy with an important reduction of the amount of waste landfilled. The SRF is the non-recyclable fraction of municipal waste and consists of approximately $30 \%$ of paper, $20 \%$ wood, $35 \%$ plastic and $15 \%$ of textile waste. It is a lightweight material with less than $20 \%$ moisture and formed by fragments of about $4 \mathrm{~cm}$. It is being tested as an alternative fuel for cement industry, but its calorific value is much lower than the petroleum coke, so that to achieve high energy substitutions must be fed a great deal more than conventional fuels. 
The SRF should have some characteristics in order to be used as a fuel for cement kilns. The most developed standard, but by all means not the only one, is the CEN/TC 343 regulation which stipulates several kinds of SRF depending on the calorific power and the presence of different pollutants, chlorine and mercury among them, being very important parameters in the operation of cement factories.

The most important characteristics of SRF destined to the cement sector are:

- High calorific power, about $16-18 \mathrm{~kJ} \mathrm{~g}^{-1}$, although some clinker plants demand higher values

- Reduced amount of chlorine (inferior to 0,5\%)

- Reduced amount of mercury (inferior to $10 \mathrm{mg} / \mathrm{kg}$, on a dry base)

This specification corresponds to high quality SRF, based on the CEN/TC 343 regulation (European Committee for Standardization). In order to be able to comply with the emission restrictions established by the legislation, the most important limitations are related to the chlorine load, because of the stable operation of the installation, as well as mercury and heavy metals presence in the SRF.

In the present paper it is studied the thermal decomposition of a SRF destined to the cement industry. It has been studied using thermogravimetry, in order to get information about the main steps in the decomposition. The study comprises two different atmospheres: inert (pyrolysis) and oxidative (combustion).

\section{Materials and methods}

\subsection{SRF characterization}

The SRF used for the development of this work was provided by the company CEMEX ESPAÑA S.A. and was obtained from three different suppliers. The SRF has a split appearance, with diverse colors because of the heterogeneity in composition. It has also a strong unpleasant odor. Prior to the characterization of the material, a representative amount of the three samples were mixed, homogenized and grounded to an average size of $1 \mathrm{~mm}$. Analyses described below were performed on this representative sample of the waste (see in Table 1 the results):

- Determination of moisture content: moisture of the sample was obtained from mass loss suffered by drying in an oven at $105^{\circ} \mathrm{C}$ until constant mass.

- Determination of ash: the solid residue obtained by calcining the sample in a muffle furnace at $850{ }^{\circ} \mathrm{C}$. 
- Elemental analysis: analysis of the major components (carbon, hydrogen, nitrogen and sulfur) is performed by oxidation of the sample to $1000^{\circ} \mathrm{C}$ and subsequent detection of combustion products $\left(\mathrm{CO}_{2}, \mathrm{H}_{2} \mathrm{O}, \mathrm{N}_{2}\right.$ and $\left.\mathrm{SO}_{2}\right)$. The equipment used was a PerkinElmer 2400 (Perkin-Elmer, UK).

- Calorific Value (NCV): determined by a calorimeter bomb AC-350 Leco Instruments.

- Determination of biomass content by analyzing the content of hemicellulose, cellulose and lignin. The contents of hemicellulose, cellulose and lignin for this material were determined according to Rowell et al. [3] and test methods T12, T222 and T203 of the "Technical Association for the Pulp and Paper Industries" [4].

\section{[Table 1]}

\subsection{Thermobalance}

SRF has been subjected to a thermal decomposition study as part of the characterization of their properties. To this end, we have carried out a series of thermogravimetric analysis in two different atmospheres: inert atmosphere of $\mathrm{N}_{2}$ and oxidative atmosphere $\mathrm{N}_{2}: \mathrm{O}_{2}=9: 1$ (10\% of oxygen) and three different heating rates every atmosphere (5, 15 and $30{ }^{\circ} \mathrm{C} \mathrm{min}{ }^{-1}$ ). Analyses were performed by simultaneous TG-DTA equipment brand METTLER TOLEDO TGA/SDTA851e/LF/1600 model that can work between room temperature and $1600{ }^{\circ} \mathrm{C}$. On this equipment the specimen holder and the oven are arranged horizontally.

\section{Results}

\subsection{TG runs and kinetics}

Six runs were performed in dynamic conditions by combining two reaction atmospheres $\left(\mathrm{N}_{2}, \mathrm{~N}_{2}: \mathrm{O}_{2}=9: 1\right)$ with three heating rates $\left(5,15\right.$ and $\left.30{ }^{\circ} \mathrm{C} \mathrm{min}^{-1}\right)$. All experiments were performed with an initial mass of about $5 \mathrm{mg}$ sample, the carrier gas flow was $100 \mathrm{~mL} \mathrm{~min}{ }^{-1}$ and the temperature range studied was from 25 to $1000^{\circ} \mathrm{C}$.

Figures 1 and 2 represent the experimental curves of mass loss versus temperature in dynamic experiments at three heating rates for each of the atmospheres of reaction studied. In the graphs, $w$ is defined as the mass fraction of solid (including both the residue formed and the unreacted solid reactant), i.e., represents the ratio between the total mass of solid at any instant 
(m) with respect to the mass initial solid $\left(\mathrm{m}_{0}\right)$. Figure 3 compares the effect of the atmosphere of reaction at $5^{\circ} \mathrm{C} \mathrm{min}^{-1}$.

[Figure 1]

[Figure 2]

[Figure 3]

The points represented, which have been those used for the kinetic analysis, have been selected according to techniques recommended by Caballero and Conesa [5] so that:

- The derivative of the points is calculated accurately and correctly.

- The points are equally spaced on a representation $\mathrm{dW} / \mathrm{dT}$ versus temperature.

- The fitting is simultaneous, with no variation of the kinetic constants, for at least three different heating rates.

Besides this, we use numerical techniques for solving differential equations and optimization methods prior definition of a proper objective function [5, 6].

In the previous graphs we can see the effect of the heating rate on TG curves. It can be appreciated that increasing heating rate curves are shifted to the right, i.e. that the mass losses occur at increasing temperatures. This behavior has been described by several researchers and can be explained using different arguments [7, 8]. Some authors argue that this behavior is due to changes in reaction mechanism caused by increased heating rate, or changes in the apparent activation energy [9]. Furthermore, poor heat transmission to the sample in the oven may cause increasing differences with increasing heating rate between the nominal and real temperature of the sample. It could also be due to different rates of heat dissipation or absorption of the reaction at different heating rate. However, the observed shift can be simply explained by the mathematical form of the kinetic laws [7, 10], which can provide a shift of the curves at higher temperatures with increasing reaction rate with the same kinetic constants.

Obviously, a kinetic model that represents a set of experiments should be able to explain such movements at various heating rates. Several authors have shown that some TG curves can be fitted to different kinetic models, providing very different values of the kinetic parameters, depending on the models used. Therefore, only models capable of explaining the shift in the TG with heating rate, without changing the kinetic parameters can be considered as potentially correct. However, if the heating rates used are very high, might be better to include heat transfer effects. In any case, the kinetic models obtained should be considered as models of data correlation, away from the claim for mechanistic models. 
In Figure 1 we can see that in the inert atmosphere the final solid residue at any heating rate is similar and close to $20 \%$, whereas in the oxidative atmosphere the amount of final solid residue is much lower, on the order of $10 \%$ (as the ash analysis in Table already indicated). From Figure 3 it is clear that the presence of oxygen accelerates the thermal decomposition of SRF, as it occurs with other materials [11-14], producing the decomposition at lower temperatures.

\subsection{Kinetic model}

Figure 1 represents the pyrolytic decomposition of the SRF. It can be distinguish three regions of mass loss. Each of these three stages would be centered at $540 \mathrm{~K}, 640 \mathrm{~K}$ and $700 \mathrm{~K}$, approximately. Due to this, the better results for the kinetic modeling will assume three different organic fractions that would decompose simultaneously in parallel reactions [8, 15]. Each organic fraction would decompose into volatile and a carbonaceous solid residue.

Using this technique, pseudo reaction mechanisms are constructed, in which each reaction includes one or more elementary reactions, since gases and tars cannot be treated separately and are grouped as volatile matter. The kinetic parameters obtained are representative of each overall reaction.

The kinetic model proposed for the pyrolysis of SRF could be interpreted considering the material formed by three independent parts, each one following an independent reaction, as follows:

$$
\begin{aligned}
& \mathrm{w}_{\mathrm{s}_{10}} \text { Solid }_{1} \stackrel{1}{\longrightarrow}\left(\mathrm{w}_{\mathrm{s}_{10}}-\mathrm{v}_{1 \infty}\right) \text { Char }_{1}+\mathrm{v}_{1 \infty} \text { Volatiles }_{1} \\
& \mathrm{w}_{\mathrm{s}_{20}} \text { Solid }_{2} \stackrel{2}{\longrightarrow}\left(\mathrm{w}_{\mathrm{s}_{20}}-\mathrm{v}_{2 \infty}\right) \text { Char }_{2}+\mathrm{v}_{2 \infty} \text { Volatiles }_{2} \\
& \mathrm{w}_{\mathrm{s}_{30}} \text { Solid }_{3} \stackrel{3}{\longrightarrow}\left(\mathrm{w}_{\mathrm{s}_{30}}-\mathrm{v}_{3 \infty}\right) \text { Char }_{3}+\mathrm{v}_{3 \infty} \text { Volatiles }_{3}
\end{aligned}
$$

In the previous reactions, Solid $_{1}$, Solid $_{2}$ and Solid $_{3}$ refer to different fractions or components of the original material, "Volatiles," are the gases and condensable volatiles evolved in the corresponding reactions ( $\mathrm{i}=1$ to 3 ), and "Char ${ }_{i}$ " is the char formed in the decomposition of each Solid $(i=1$ to 3 ). On the other hand, the small letters represent the yield coefficients representative of each reaction and consequently, it is considered not to be changing with time and with the extension of the reaction. Moreover, each fraction has a yield coefficient that represents the maximum mass fractions obtainable by each reaction. In this way, $\mathrm{v}_{\mathrm{i} \infty}$ is the yield coefficient for the Volatiles ${ }_{i}$ and $v_{i}$ is the mass fraction of volatiles. The different initial mass fraction of the components $\left(\mathrm{w}_{\mathrm{sio}}\right)$ are related so the following must be fulfilled: 


$$
\sum_{i=1}^{3} w_{s_{i 0}}=1
$$

Considering an n-th order kinetic decomposition, the kinetic equations for the pyrolysis runs can be expressed as followed:

$$
-\frac{d w_{s_{i}}}{d t}=k_{i} w_{s_{i}}^{n_{i}}
$$

Or

$$
\frac{d V_{i}}{d t}=k_{i}\left(V_{i \infty}-V_{i}\right)^{n_{i}}
$$

with the kinetic constants following the Arrhenius equation:

$$
\mathrm{k}_{\mathrm{i}}=\mathrm{k}_{\mathrm{i} 0} \exp \left(-\frac{\mathrm{E}_{\mathrm{i}}}{\mathrm{RT}}\right) \quad \mathrm{i}=1 \text { to } 3
$$

In the equations, $V_{i}$ and $V_{i \infty o}$ represent the volatiles evolved from the decomposition of each fraction, and the maximum yield of volatiles that can be obtained, respectively.

For the optimization of 3 TG runs (approx. 300 experimental points), 11 parameters were obtained $\left(3 \times \mathrm{E}_{\mathrm{i}}, 3 \mathrm{x} \mathrm{k}_{\mathrm{i} 0}, 3 \mathrm{x} \mathrm{n}_{\mathrm{i}}\right.$ and $\left.2 \mathrm{x} \mathrm{w}_{\mathrm{si}}\right)$.

On the other hand, the model proposed to explain the thermal decomposition of SRF in the presence of oxygen is the same that has been considered in the case of pyrolysis runs, but with different values of the kinetic constants.

In order to obtain a single set of parameters for the combustion of the material, all the runs were correlated with the same set of parameters by a similar procedure explained with the correlation of the pyrolysis data. For all the fractions (1 to 3), the same values of apparent activation energy and reaction order obtained under a nitrogen atmosphere have been considered, but the preexponential factor could change due the presence of the oxygen. This type of model satisfactorily fitted the decomposition of other materials $[16,17]$. With all these considerations, acceptable correlations of the data are obtained.

The calculated values were obtained by integration of the differential equations presented in the kinetic model, by the explicit Euler method, but considering and testing that the intervals of time are small enough so the errors introduced are negligible. The optimization method of the function Solver in a Microsoft Excel spreadsheet was used to minimize the differences between 
experimental and calculated mass loss and their derivatives. The objective function (OF) to minimize was the sum of the square differences between experimental and calculated mass loss values:

$$
\text { O.F. }=\sum_{j} \sum_{k}\left[w_{\exp _{k j}}-w_{c a l} c_{k_{j}}\right]^{2}
$$

where ' $k$ ' represents the experimental data at time ' $t$ ' in the experiment with a heating rate ' $j$ '. The value of $\mathrm{w}_{\text {expkj }}$ or $\mathrm{w}_{\text {calkj }}$ represents the mass loss fraction in the experimental and calculated data, respectively.

The kinetic parameters for decomposition of each fraction are shown in Table 2. As mentioned above, the same activation energy and reaction order are assumed for pyrolysis and combustion processes. Figure 4 shows the loss curves of experimental and calculated mass, at all heating rates studied and both in inert and oxidative atmosphere. It is clear that best fits would be obtained if all parameters are allowed to vary for each run, but they would be less representative of the overall process.

\section{[Figure 4]}

\section{Discussion}

The values of activation energies obtained from the fitting are $324.9 \mathrm{~kJ} \mathrm{~mol}^{-1}, 98.1 \mathrm{~kJ}$ $\mathrm{mol}^{-1}$ and $274.3 \mathrm{~kJ} \mathrm{~mol}^{-1}$ and correspond to the fractions discussed above.

Figures $5 \mathrm{a}$ and $5 \mathrm{~b}$ show the decomposition of each fraction calculated for the pyrolysis and combustion processes at the three heating rates considered.

\section{[Figure 5]}

The first fraction, comparable to hemicellulose, decomposes in a temperature range of $200-250{ }^{\circ} \mathrm{C}$ for the combustion and $250-300{ }^{\circ} \mathrm{C}$ for the pyrolysis process. The data are consistent with the literature consulted [18]. The reaction order for this fraction is close to unity, as it is accepted for this type of material $[8,15,19,20]$.

The second fraction, mainly composed of cellulose, decomposes in a temperature range of $300-350{ }^{\circ} \mathrm{C}$ for pyrolysis and reaches $400{ }^{\circ} \mathrm{C}$ for high speed heating in combustion because the main reactions involve breakage of glycosidic linkages with the consequent partial depolymerization of the cellulosic component of wood [21, 22]. 
The third fraction, similar to lignin, is the most refractory and difficult to degrade by thermal route. The highest percentage of fixed carbon present in wood with higher percentages of lignin, which are attributed to the lignin being the most resistant to thermal decomposition when compared with cellulose and hemicellulose, due to its highly complex structure. This fraction decomposes between 400 and $900 \mathrm{~K}$ in both pyrolysis and combustion, presenting the highest range of temperature decomposition. The reaction order is high as previously reported for ligninic materials [8].

The values of the preexponential factors of all the organic fractions considered increase with the partial pressure of oxygen. This indicates that exists an acceleration of the process in the presence of oxygen, as pointed out previously. From the data presented in Table 2 it is possible to calculate the following "Enhancement factor":

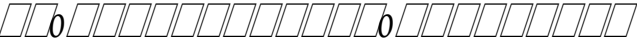

that will give an idea of the effect of oxygen in the decomposition rate. The values of this EF are 2.2, 3.1 and 26.1 for fractions 1,2 and 3 respectively, denoting that the fraction that most increases the decomposition rate in the presence of oxygen is fraction 3 , similar to lignin.

\section{Conclusions}

A thermogravimetric study on the decomposition of a solid recovered fuel has been done at different heating rates and atmospheres. A kinetic model for decomposition in inert and oxidizing atmosphere is proposed. The model assumes the presence of three organic fractions in the SRF, which will be assimilated to cellulosic, hemicellulosic and ligninic species. The decomposition of each fraction is produced by an $\mathrm{n}^{\text {th }}$ order kinetic law. The mathematical treatment of the data permits to fit simultaneously pyrolysis and combustion experimental data. The combustion is much more rapid than the pyrolysis, and the ligninic fraction is the most affected by the presence of oxygen.

\section{Aknowledgements}

Authors acknowledge the financial support for this work provided by PROMETEOII/2014/007 of Generalitat Valenciana (Spain) and CTQ2013-41006-R (Spanish Ministry of Economy and Competitiveness). The authors are also grateful to CEMEX ESPAÑA, S.A. for supplying the samples. 


\section{Literature cited}

1. Blumenthal KB, L. (Eurostat). Waste indicators on generation and landfilling measuring sustainable development 2004-2010. Environment and Energy. 2013.

2. Eurostat. Waste 2013. http://epp.eurostat.ec.europa.eu/statistics_explained/index.php/Waste_statistics

3. Rowell RM, Rowell JK, Young RA. Paper And Composites From Agrobased Resources. CRC Press; 1996.

4. TAPPI. a-, b- and g- cellulose in pulp. Atlanta, US: TAPPI Press; 1978.

5. Caballero JA, Conesa JA. Mathematical considerations for nonisothermal kinetics in thermal decomposition. Journal of Analytical and Applied Pyrolysis. 2005; 73(1):85-100.

6. Várhegyi G, Szabó P, Jakab E, Till F. Least squares criteria for the kinetic evaluation of thermoanalytical experiments. Examples from a char reactivity study. Journal of Analytical and Applied Pyrolysis. 2001;57(2):203-22.

7. Conesa JA, Caballero JA, Marcilla A, Font R. Analysis of different kinetic models in the dynamic pyrolysis of cellulose. Thermochimica Acta. 1995; 254(C): 175-92.

8. Caballero JA, Conesa JA, Font R, Marcilla A. Pyrolysis kinetics of almond shells and olive stones considering their organic fractions. Journal of Analytical and Applied Pyrolysis. 1997; 42(2): 159-75.

9. Suriapparao DV, Ojha DK, Ray T, Vinu R. Kinetic analysis of co-pyrolysis of cellulose and polypropylene. J Therm Anal Calorim. 2014; 117(3): 14411451

10. Caballero JA, Font R, Marcilla A, Conesa JA. New kinetic model for thermal decomposition of heterogeneous materials. Industrial and Engineering Chemistry Research. 1995;34(3):806-12.

11. Conesa JA, Font R, Fullana A, Caballero JA. Kinetic model for the combustion of tyre wastes. Fuel. 1998; 77(13):1469-75.

12. Aracil I, Font R, Conesa JA. Thermo-oxidative decomposition of polyvinyl chloride. Journal of Analytical and Applied Pyrolysis. 2005; 74(12): 215-23.

13. Jauhiainen J, Conesa JA, Font R, Martin-Gullon I. Kinetics of the pyrolysis and combustion of olive oil solid waste. Journal of Analytical and Applied Pyrolysis. 2004; 72(1): 9-15. 
14. Font R, Fullana A, Conesa JA, Llavador F. Analysis of the pyrolysis and combustion of different sewage sludges by TG. Journal of Analytical and Applied Pyrolysis. 2001; 58-59: 927-41.

15. Várhegyi G, Antal J r MJ, Jakab E, Szabó P. Kinetic modeling of biomass pyrolysis. Journal of Analytical and Applied Pyrolysis. 1997;42(1):73-87.

16. Aracil I, Font R, Conesa JA, Fullana A. TG-MS analysis of the thermooxidative decomposition of polychloroprene. Journal of Analytical and Applied Pyrolysis. 2007; 79(1-2 SPEC. ISS.): 327-36.

17. Conesa JA, Moltá J, Font R, Egea S. Polyvinyl chloride and halogen-free electric wires thermal decomposition. Industrial and Engineering Chemistry Research. 2010;49(22): 11841-7.

18. Zanzi R, Sjöström K, Björnbom E. Rapid high-temperature pyrolysis of biomass in a free-fall reactor. Fuel. 1996; 75(5):545-50.

19. Várhegyi G, Chen H, Godoy S. Thermal decomposition of wheat, oat, barley, and brassica carinata straws. a kinetic study. Energy Fuels. $2009 ; 23(2): 646-52$.

20. Várhegyi G, Czégény Z, Jakab E, McAdam K, Liu C. Tobacco pyrolysis. Kinetic evaluation of thermogravimetric-mass spectrometric experiments. Journal of Analytical and Applied Pyrolysis. 2009; 86(2):310-22.

21. Shafizadeh F, Sekiguchi Y. Oxidation of chars during smoldering combustion of cellulosic materials. Combust Flame. 1984;55(2):171-9.

22. Pitman WD, Soltes EJ, Holt EC. Mannose in the holocellulose of Panicum coloratum. Phytochemistry. 1981;20(5):1129-30. 


\section{LIST OF TABLES AND FIGURES}

Table 1. SRF characterization

Table 2. Kinetic parameters for pyrolysis and combustion (all heating rates)

Figure 1. TG curve for SRF in N2 at 5, 15 and $30{ }^{\circ} \mathrm{C} \mathrm{min}^{-1}$

Figure 2. TG curve for SRF in N2:O2 at 5, 15 and $30{ }^{\circ} \mathrm{C} \mathrm{min}{ }^{-1}$

Figure 3. TG curves at $5{ }^{\circ} \mathrm{C} \min ^{-1}$ under an atmosphere of $\mathrm{N}_{2}$ and $\mathrm{N}_{2}: \mathrm{O}_{2}=9: 1$

Figure 4. Comparison of experimental and calculated values of normalized mass loss in the pyrolysis and combustion runs.

Figure 5. Decomposition of each fraction assumed in the kinetic modeling at the different experimental conditions. 
Table 1. SRF characterization

\begin{tabular}{|c|c|}
\hline Moisture / wt. \% & 16.67 \\
\hline $\mathrm{NCV} / \mathrm{kJ} \mathrm{kg}^{-1}$ & 1014.2 \\
\hline Ash / wt. \% & 10.23 \\
\hline Element & wt. \% \\
\hline $\mathrm{N}$ & 1.07 \\
\hline $\mathrm{C}$ & 40.85 \\
\hline $\mathrm{H}$ & 5.33 \\
\hline $\mathrm{S}$ & 0.15 \\
\hline O (by difference) & 42.37 \\
\hline Metal & $\mathrm{mg} \mathrm{kg}^{-1}$ \\
\hline $\mathrm{V}$ & 15 \\
\hline $\mathrm{Cr}$ & 78 \\
\hline Mn & 354 \\
\hline Co & 4 \\
\hline $\mathrm{Ni}$ & 52 \\
\hline $\mathrm{Cu}$ & 240 \\
\hline $\mathrm{Zn}$ & 658 \\
\hline As & 25 \\
\hline $\mathrm{Cd}$ & 2 \\
\hline $\mathrm{Sn}$ & 18 \\
\hline $\mathrm{Sb}$ & 32 \\
\hline $\mathrm{Tl}$ & 4 \\
\hline $\mathrm{Hg}$ & 0,2 \\
\hline $\mathrm{Te}$ & 2 \\
\hline $\mathrm{Pb}$ & 235 \\
\hline \% biomass in SRF & 86.5 \\
\hline \% Lignin in biomass & 31.3 \\
\hline \% Cellulose in biomass & 61.1 \\
\hline \% Hemicelulose in biomass & 7.6 \\
\hline
\end{tabular}


Table 2. Kinetic parameters for pyrolysis and combustion (all heating rates)

\begin{tabular}{|c|c|c|c|}
\hline & \multirow{3}{*}{$\begin{array}{l}\text { Pyrolysis } \\
7.15 \cdot 10^{20}\end{array}$} & \multirow{3}{*}{$\frac{\text { Combustion }}{1.63 \cdot 10^{21}}$} \\
\hline & & & \\
\hline \multirow{4}{*}{ fraction 1} & $\mathrm{k}_{0} / \min ^{-1}$ & & \\
\hline & $\mathrm{E} / \mathrm{kJ} \mathrm{mol}^{-1}$ & \multicolumn{2}{|c|}{324.9} \\
\hline & $\mathrm{W}_{\mathrm{io}}$ & \multicolumn{2}{|c|}{0.19} \\
\hline & $\mathrm{N}$ & \multicolumn{2}{|c|}{0.70} \\
\hline \multirow{4}{*}{ fraction 2} & $\mathrm{k}_{0} / \min ^{-1}$ & $2.23 \cdot 10^{6}$ & $6.92 \cdot 10^{6}$ \\
\hline & $\mathrm{E} / \mathrm{kJ} \mathrm{mol}^{-1}$ & \multicolumn{2}{|c|}{98.1} \\
\hline & $\mathrm{w}_{\mathrm{io}}$ & \multicolumn{2}{|c|}{0.48} \\
\hline & $\mathrm{N}$ & \multicolumn{2}{|c|}{0.76} \\
\hline \multirow{4}{*}{ fraction 3} & $\mathrm{k}_{0} / \min ^{-1}$ & $1.58 \cdot 10^{18}$ & $4.13 \cdot 10^{19}$ \\
\hline & $\mathrm{E} / \mathrm{kJ} \mathrm{mol}^{-1}$ & \multicolumn{2}{|c|}{274.3} \\
\hline & $\begin{array}{c}\mathrm{w}_{\mathrm{io}} \text { (by } \\
\text { difference) }\end{array}$ & \multicolumn{2}{|c|}{0.33} \\
\hline & $\mathrm{n}$ & \multicolumn{2}{|c|}{2.87} \\
\hline
\end{tabular}




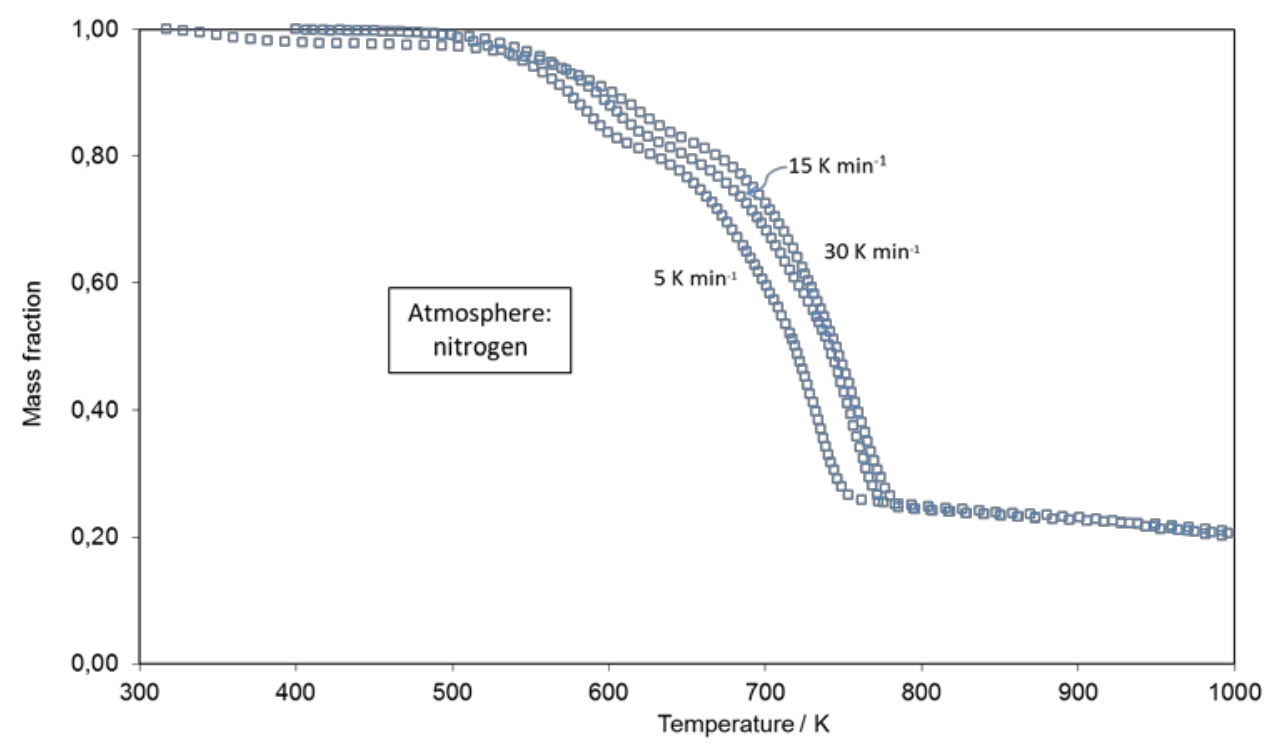

Figure 1. TG curve for SRF in $\mathrm{N}_{2}$ at 5,15 and $30 \mathrm{~K} \mathrm{~min}^{-1}$

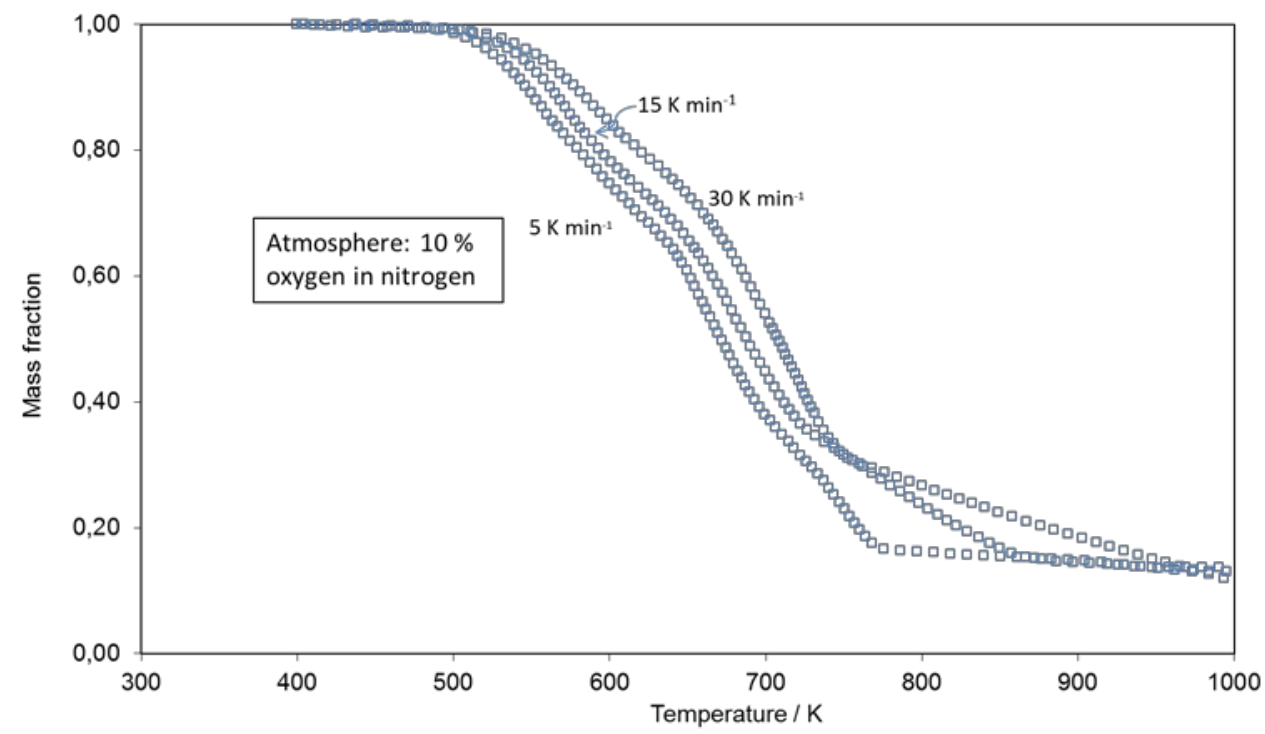

Figure 2. TG curve for SRF in $\mathrm{N}_{2}: \mathrm{O}_{2}$ at 5,15 and $30 \mathrm{~K} \mathrm{~min}^{-1}$ 


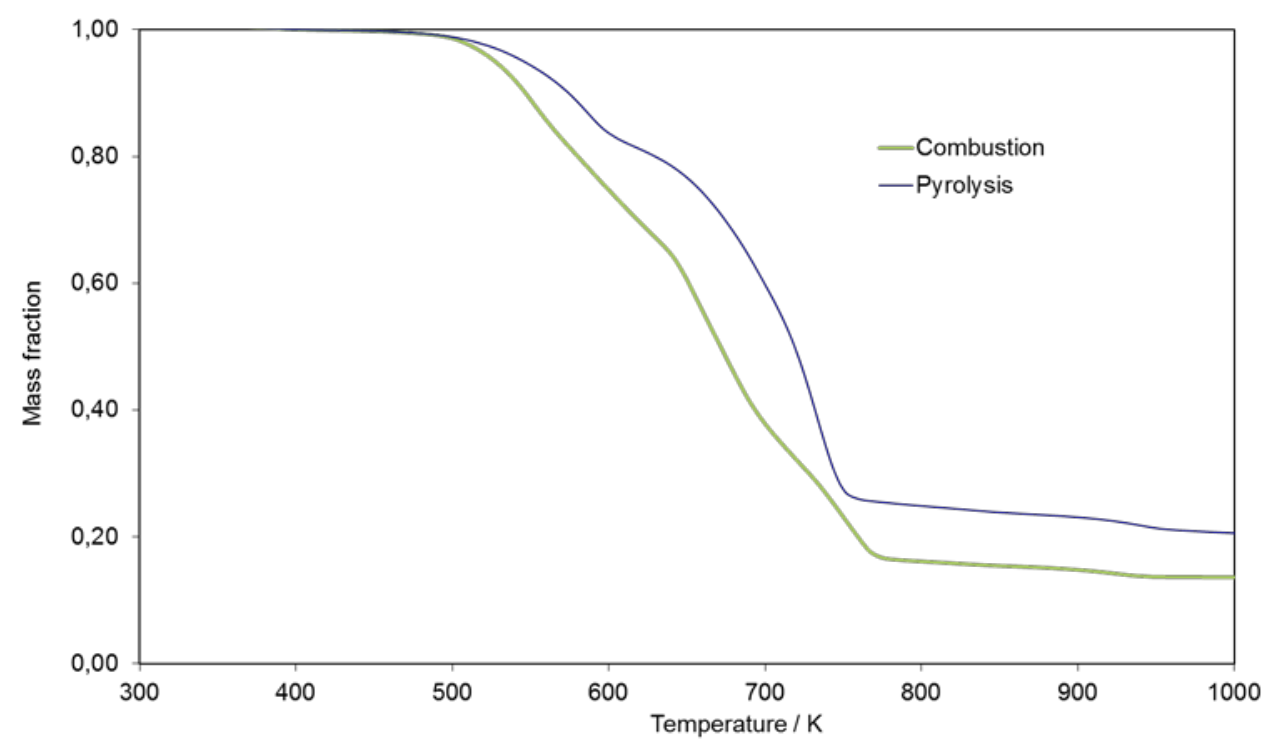

Figure 3. TG curves at $5 \mathrm{~K} \mathrm{~min}^{-1}$ under an atmosphere of $\mathrm{N}_{2}$ and $\mathrm{N}_{2}: \mathrm{O}_{2}=9: 1$

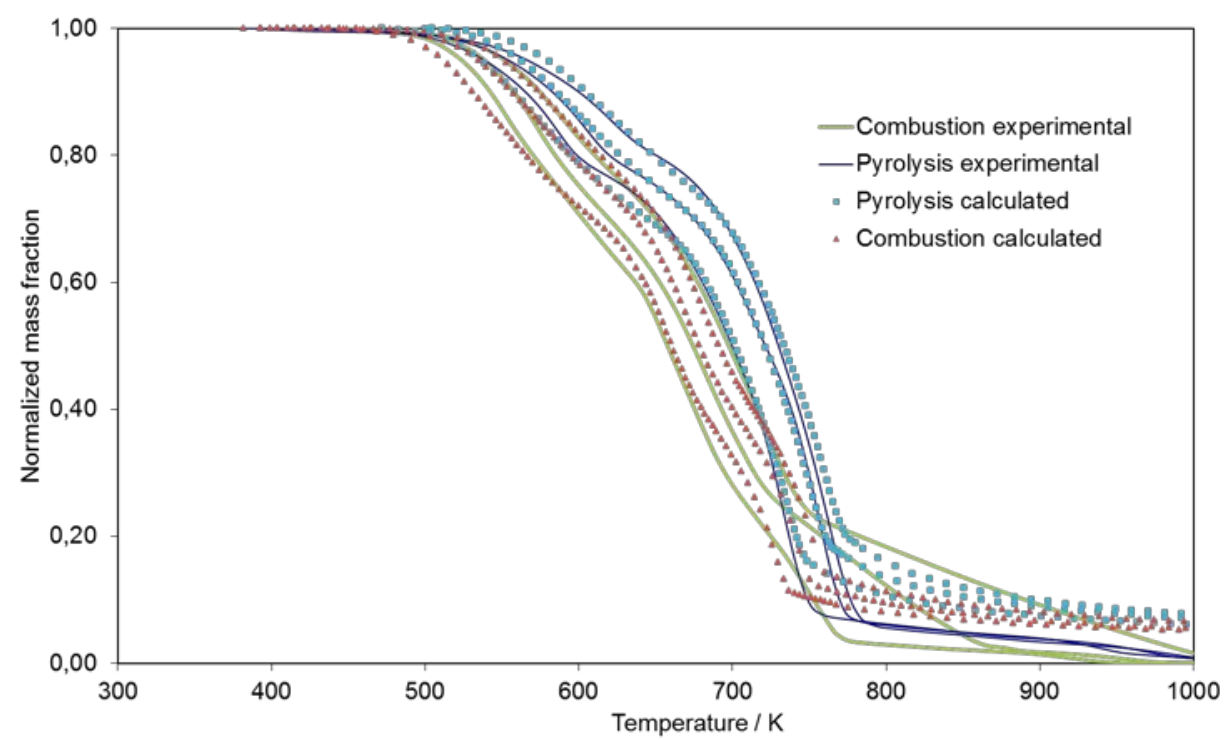

Figure 4. Comparison of experimental and calculated values of normalized mass loss in the pyrolysis and combustion runs. 

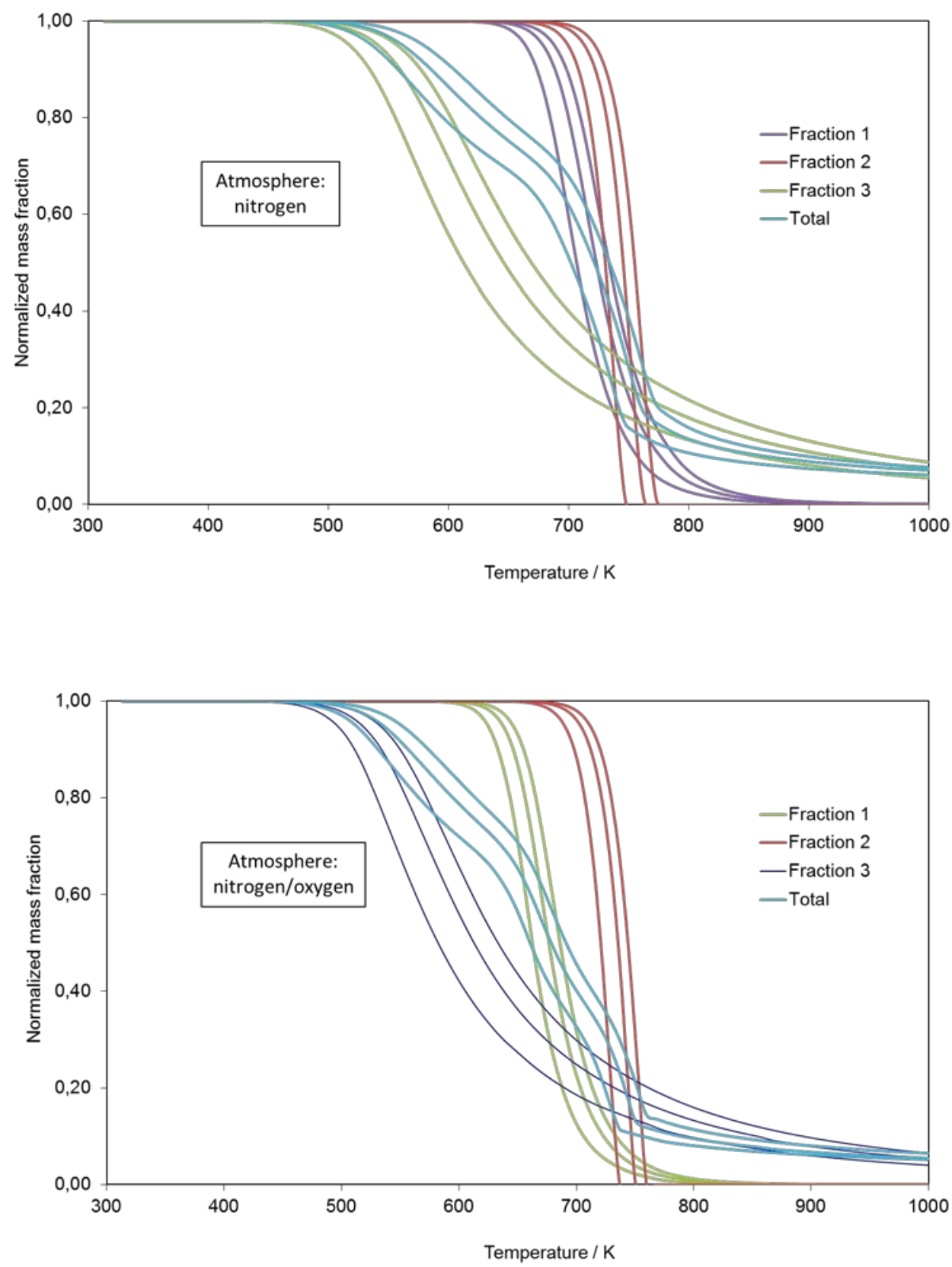

Figure 5. Decomposition of each fraction assumed in the kinetic modeling at the different experimental conditions. 